along the dry beds of rivers, but frequent storms, which in Jehol turned scorching summer to bitter cold, often delayed or prevented a projected tour. "A proverb goes 'a precipice in front, a wolf behind' ; when our march was impeded, we could not safely stay where we were because of there being a danger of bandits' assault". The expedition's work was done under escort of thirty soldiers and occasionally under additional protection from garrisons.

Dirty and scarce drinking water, and "horribly poisonous insects", with the concomitant troubles of dysentery, trachoma, etc., were probably greater difficulties than the bandits, who only fired upon a camp on one occasion. An endemic epidemic goitre was found to be widespread in south-western Jehol.

The preliminary scientific results are summarised by the head of each section in the first general report (October 1934). A brief stratigraphical summary reports abundant fossil Lycoptera and many fossil insect larvæ (Ephemeropsis) in lower Cretaceous rocks. In loess strata of Middle Pleistocene age, remains of Ovis and Elephas included bone pieces apparently engraved by ancient man. Jehol was a nomad zone originally occupied by Mongolians ; during the Shin dynasty, these Mongolians had declined in prosperity and the Hans (Chinese in the Han dynasty) emigrated there. In the northern district of Manchoukuo the Mongolians still predominate, and throughout the country three systems of farming can be traced, the North Chinese, Manchurian and Mongolian. The animals found still recall the forests, which have been ruthlessly despoiled since the Hans. The November report (Section 4, Part 1) figures and describes eight species of new woody plants (by Dr. T. Nakai) and twenty-nine new herbaceous plants (by Dr. T. Nakai and M. Kitagawa).

Section 5, part 1, consists of an account of the freshwater fishes of the province of Jehol. This province-a highland area occupying the southwestern part of Manchoukuo and contiguous with the north-eastern border of the Chinese province of Hopei (Chili)-is irrigated by the upper reaches of several rivers in the waters of which and those of associated lakes and ponds $\mathbf{7 8 3}$ fishes were collected. These comprised 33 species and one sub-species representative of the two families Cyprinidæ and Ophicephalidæ. The detailed taxonomic descriptions are accompanied by twenty-one beautifully produced plates in which all the species are carefully figured, some of them in colour.

\section{Lubricating Value of Mineral Oils}

$\mathrm{I}^{\mathrm{N}}$ 1929, under the auspices of the Department of Scientific and Industrial Research, a paper (Lubrication Research, Technical Paper No. 1) by the late Sir William Hardy and M. E. Nottage on the analysis of commercial lubricating oils by physical methods was prepared. It was considered, however, inadvisable to draw conclusions from the results of experiments reported therein, since only two oils, and those of unknown origin, had been employed. A further paper by Miss Nottage recently published under similar conditions (Lubrication Research, Technical Paper No. 2. London: H.M. Stationery Office. 9d. net) entitled "A Study of the Boundary Lubricating Value of Mineral Oils of Different Origin" is intended in certain respects to supplement the original one.

When the film of lubricating oil separating two smooth bearing surfaces is so thin that no part of it is beyond the range of cohesive forces of attraction transmittable from these surfaces, boundary conditions are said to prevail. Interposition between the two surfaces of a film of oil may, to some extent, neutralise these conditions or, in other words, boundary lubrication may be employed. In these circumstances two important factors must be taken into consideration: the effect of the surface on the oil, hence the nature of the bearing surface, since chemical activity occurring at an interface differs materially from that occurring in bulk; and chemical properties of the lubricant, the function of which of neutralising the cohesive forces of attraction is effected by the formation of adsorptive layers on the bearing surfaces.

Inasmuch as mineral lubricating oils consist of inactive, non-polar constituents and surface-active polar constituents, from which the greater part of the adsorptive layer is formed, the properties of the film may differ considerably from properties of the oil in bulk. Important factors determining frictionreducing properties of the adsorptive layer are the chemical nature of the constituents and their degree of dispersion. This, in turn, may be varied by changes of temperature, the presence of other substances which play no part in reducing friction, or the solution of oil in certain volatile solvents.

Having regard to the important part played by wax in mineral oils, concurrent investigations were made to obtain some indication of its rôle in a lubricant under boundary conditions. It is shown that, in spite of the general view that wax is detrimental to a lubricant, it does, in certain cases, enhance the lubricating value of the oil at the boundary layer.

\section{University and Educational Intelligence}

Cambridge.-At St. John's College a research studentship and research exhibitions are offered for competition in July 1935. One Strathcona research studentship of the annual value of $£ 150$ is offered for competition among research students who are graduates of any university other than Cambridge. Two Strathcona exhibitions of the annual value of $£ 40$ are also offered for competition under the same conditions as the studentship.

Grants from the Worts Fund have been made as follows :- $£ 75$ to D. B. Keith, A. B. Whatman, and J. W. Wright towards the expenses of an expedition to survey the north coast of North-East Land (Spitsbergen); £120 to P. T. Cotton, D. W. Ewer and L. E. R. Picken towards the expenses of an expedition to investigate the freshwater ecology of the southwest Balkans; $£ 50$ to T. T. Paterson towards the expenses of an expedition to the North-West Frontier of India for the purpose of studying quaternary deposits; $£ 2610 s$. to J. R. B. Stewart for archæological investigations in Asia Minor ; £25 to Dr. T. C. Phemister towards the expenses of a geological and petrological survey of the Coast Range batholith of British Columbia; $£ 25$ to T. G. Tutin for a visit to the Mediterranean coast of Spain to study the destruction of the eel-grass, Zostera marina; $£ 25$ to K. H. Chapman for an expedition to Morocco to study the Moroccan locust, Dociostaurus morocannus.

J. H. Lockhead, of Christ's College, has been nominated to use the University's table at the Zoological Station at Naples. 
London.--Mr. R. O. Kapp has been appointed as from March 1 to the Pender chair of electrical engineering tenable at University College.

THE Board of Education is prepared, as in recent years, to consider applications for full-time studentships from teachers in England and Wales with at least five years teaching experience who desire financial assistance to follow courses of advanced study at universities or other institutions at home or abroad. Particulars of the awards and application forms are obtainable from the Board of Education, Whitehall, S.W.1.

Applications, which must be received not later than April 15, are invited for the following scholar. ships awarded by the Council of the Institution of Electrical Engineers. Further particulars can be obtained from the Secretary of the Institution, Savoy Place, London, W.C.2. Duddell Scholarship, valued at $£ 150$ a year and tenable for three years, open to British subjects under nineteen years of age on July 1, 1935, who wish to take up a whole-time day course in electrical engineering ; Ferranti Scholarship, valued at $£ 250$ a year and tenable for two years, open to British subjects under twenty-six years of age on July 1, who desire to carry out whole-time research or post-graduate work in electrical engineering. Swan Memorial Scholarship, valued at $£ 120$, and for one year, open to British subjects under twenty-seven years of age on July 1, who desire to carry out whole-time research or post-graduate work in electrical engineering. Silvanus Thompson Scholarship, valued at $£ 100$ a year and tuition fees, tenable for two years, for works employees, open to British subjects under twenty-two years of age on July 1 ; the successful candidate will be required to take up a whole-time day course in electrical engineering at an approved university or technical college.

From Heriot-Watt College, Edinburgh, we have received a brochure signalising the completion and opening, in January, of the first section of an important extension of the College buildings, planned, in conjunction with the Town Council, in 1928. The second section, to be completed, it is hoped, in 1936, has already been begun, and the governors propose to make now an appeal for the sum of $£ 100,000$ to finance the construction and equipment of the final section. The appeal will be associated with the celebration of the fiftieth anniversary of the assumption by the College of its present name and functions. Prior to 1886 , the institution was concerned mainly with evening classes for young persons employed during the day in earning their living, and without any other means of advancing beyond the standards of education of the elementary schools. The pamphlet gives, in addition to full particulars of the extension scheme, a very interesting account of the stages through which the 'School of Arts', founded in 1821 by Leonard Horner (afterwards first principal of University College, London), gradually reached its present status - that of an affiliated college of the University of Edinburgh, preparing students for careers in mechanical, electrical, mining and oil engineering, applied chemistry, brewing, pharmacy, building and printing and conducting evening classes in commerce. Special prominence is given to the amplitude, due in large measure to the exertions of the late Edward Clark, of the equipment of the printing school for the teaching of all phases of book production.

\section{Science News a Century Ago}

\section{Chemistry of the Sea}

The chemical composition of sea and mineral waters was being actively investigated by Dr. Daubeny in the years 1835-37. In his manuscript "Note-book of Experiments" he records, "March 25th. Having brought from Naples a bottle containing the residuum of 2 gallons of the sea-water taken off the Island of Ischia evaporated till there remained only 6 ounces, I tested it for Bromine . . I obtained $5 \cdot 1$ grains of silver precipitate - chiefly bromide." From previous analyses it appeared that there is an almost exact correspondence between the quantity of bromine present in the sea-water off Southampton and off Naples.

\section{Temperature of Fishes}

Dr. John Davy (1790-1868), the brother of Sir Humphry Davy, became an army surgeon and rose to the rank of inspector-general of army hospitals. $\mathrm{He}$ was eminent as a chemist, geologist and physiologist, and in 1834 was elected a fellow of the Royal Society. On March 26, 1835 , he read a paper to the Royal Society "On the Temperature of some Fishes of the Genus Thunnus". He said that many years before he had observed that the bonito had a temperature of $99^{\circ} \mathrm{F}$. when the surrounding medium was $80.5^{\circ} \mathrm{F}$. and that it, therefore, constituted an exception to the general rule that fishes are universally cold-blooded. Having found that the gills of the common tunny of the Mediterranean were supplied with nerves of unusual magnitude, that the heart of this fish was very powerful and that its muscles were of a dark red colour, he was led to conjecture that it might, like the bonito, be also warm-blooded, and this opinion was corroborated by the testimony of several intelligent fishermen. In the course of his paper he endeavoured to extend the analogy to other species of the same family which, according to the reports of the fishermen of whom he made inquiries, have a high temperature and in the internal structure of which he noticed the same peculiarities as in the tunny, namely, very large branchial nerves, furnished with ganglia of considerable size.

\section{Faraday on the Manufacture of Pens}

On March 27, 1835, Faraday lectured at the Royal Institution on the manufacture of pens. A report of the lecture was given in the Records of General Science of May 1835. Quills, Faraday said, appear to have been employed at least as early as the seventh century. England was supplied with the article from Russia and Poland, where immense flocks of geese were kept for the sake of their quills. Twenty million quills were imported into England from those countries in 1834. A wing of a goose produced about five good quills, and by proper management, a goose might afford twenty quills during the year. The preparation of quills was a nice process of which, up to seventy years previously, the Dutch had had a monopoly. A pen cutter would eut about 1,200 quills a day. A house in Shoe Lane cut annually about six million. Steel pens for writing were first made by Mr. Wise in 1803, and were fashioned like goose pens. A patent was taken out in 1812 for pens with flat cheeks, and in this way all metallic pens were made for some time, as the rhodium pen of Dr. Wollaston and the iridium pens of others. About twelve years 